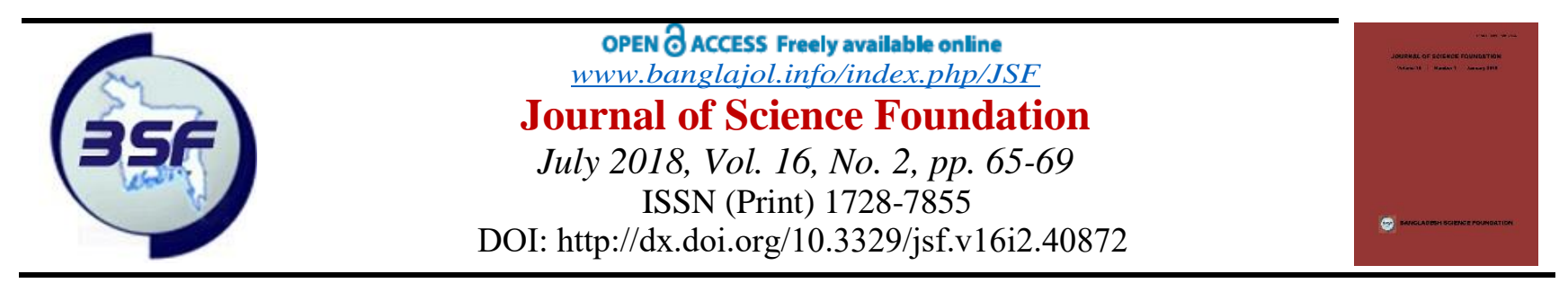

Original Article

\title{
Obstetrics Factors Related with Pelvic Inflammatory Disease Patients
}

\author{
Nadira Khan ${ }^{1}$, Firoza Rahman ${ }^{2}$, Nilufar Jahan ${ }^{3}$, Rahela Khatun ${ }^{4}$, Shafeya Khanam ${ }^{5}$
}

\begin{abstract}
Background: Pelvic Inflammatory disease is a very common gynaecological condition among the women. Objectives: The purpose of the present study was to see the obstetrics factors related with the pelvic inflammatory disease. Methodology: This cross-sectional study was carried out in the Department of Obstetrics and Gynaecology at Dhaka Medical College Hospital, Dhaka, Bangladesh from November 2001 to April 2002 during the period of six (06) months and December 2002 to February 2003 for three (03) months with the total duration of nine (09) months. Women in child bearing age who were suffering from chronic pelvic inflammatory disease (PID) attended at the OPD of gynecology Department at Dhaka Medical College Hospital, Dhaka, Bangladesh were selected as study population. Relevant data from each patient were recorded in a questionnaire. Result: A total number of 150 cases were studied. Out of 146 patients $75.3 \%$ were delivered at home, $8.2 \%$ at hospital and $16.4 \%$ cases had their deliveries at home and at hospital also. Out of 146 patients $63.0 \%$ were delivered by untrained birth attendants at home and $36.99 \%$ were delivered by trained birth attendants. Out of 146 patients $54.1 \%$ had history of puerperal sepsis. However, the rest of the $67(45.9 \%$ ) cases were normal puerperium. In this study $84.0 \%$ patients had history of MR, 18 percent had spontaneous abortion and 4.7 percent had induced abortion. Out of these 115 patients with history of pregnancy termination, $47.3 \%$ patients had history of pelvic infection following that event. Also, $2.7 \%$ gave history of ectopic pregnancy. Conclusion: In conclusion most of the PID patients are delivered at home with untrained birth attendants with the history of puerperal sepsis. [Journal of Science Foundation 2018;16(2):65-69]
\end{abstract}

Keywords: Pelvic Inflammatory disease; obstetrics factors; puerperal sepsis; untrained birth attendants

[Reviewed: 3 February 2018; Accepted on: 1 March 2018; Published on: 1 July 2018]

\section{Introduction}

PID is an ascending infection in which pathogenic microorganisms ascend from the lower genital tract to the upper genital tract (Brunham 2015). Endometritis is an early manifestation of PID and most but not all women with PID have plasma cell endometritis. Salpingitis develops, which can lead to pyosalpinx or tubo-ovarian abscess formation. Perihepatitis is associated with PID in 10-20\% of cases (Soper 2010).

\footnotetext{
${ }^{1}$ Senior Consultant, Family Planning Model Clinic, Sir Salimullah Medical College \& Mitford Hospital, Dhaka, Bangladesh ${ }^{2}$ Emergency Medical Officer, Dhaka medical College, Dhaka, Bangladesh

${ }^{3}$ Medical Officer, Family Planning Model Clinic, Sir Salimullah Medical College \& Mitford Hospital, Dhaka, Bangladesh

${ }^{4} J u n i o r$ Consultant (Gynaecology \& Obstetrics), National Institute of Cancer Research \& Hospital, Dhaka, Bangladesh

${ }^{5}$ Associate Professor, Department of Gynaecology \& Obstetrics, Faridpur Medical College, Faridpur, Bangladesh
}

Correspondence: Dr. Nadira Khan, Senior Consultant, Family Planning Model Clinic, Sir Salimullah Medical College \& Mitford Hospital, Dhaka, Bangladesh; Email: ashabori2003@yahoo.com; Cell no.: +8801711275426

Copyright: (02018. Khan et al. Published by Journal of Science Foundation. This article is distributed under the terms of the Creative Commons Attribution 4.0 International CC BY-NC License (https://creativecommons.org/licenses/by-nc/4.0/). This license permits unrestricted use, distribution and reproduction in any medium, provided the original work is properly cited, you give appropriate credit to the original author(s) and is not used for commercial purposes. 
Factors associated with PID mirror those for sexually transmitted infections. Risk factors and risk markers for PID are an increase in world population, population have tended to become urbanized, attitudes to sex have changed, and the age of commencing sexual activity has fallen; multiple sexual partners, travel has increased and casual sexual encounters are much more common away from home, menstruating teenagers, absence of barrier contraceptive use, current or recent use of IUCD, previous history of acute PID, area with high prevalence of sexually transmitted diseases, previous history of STD and recent operative procedures like MR, termination of pregnancy or delivery (Brunham 2015).

In Bangladesh, about $90.0 \%$ deliveries are conducted by untrained birth attendants in a very unhygienic condition (Brunham 2015). Most of the women are not cautious or particular to use various family planning methods especially in rural areas. So there is a gradual increased incidence of unplanned pregnancies and MR, induced abortions which are mostly done by unskilled persons in unhygienic environment with unsterile instruments and with some dangerous foreign bodies. So the prevalence and clinical profile of PID in developing countries may be different from those of developed countries (Fortner 2007).

Sequelae of PID can sometimes be very pathetic, as it causes subfertility which is a very gloomy event in reproductive health of a woman, as well as for her family life. It can cause pelvic and generalized peritonitis, septic shock; chronic pelvic pain which disturbs day to day activities of a woman. PID can cause dyspareunia which disturbs marital harmony. It may also cause ectopic pregnancy, pelvic abscess and tuboovarian mass necessitates major surgeries by which mortality and morbidity is further increased. Pelvic inflammatory disease is really a serious reproductive health hazard globally, which should be prevented and managed meticulously to improve the quality of reproductive health of millions of women worldwide. The cost which has to spend for the treatment of PID in any country is an impact on the nation.

\section{Methodology}

This study was designed as descriptive cross-sectional study. It was carried out in the Department of Obstetrics and Gynaecology at Dhaka Medical College Hospital, Dhaka, Bangladesh from November 2001 to April 2002 during the period of six (06) months and December 2002 to February 2003 for three (03) months with the total duration of nine (09) months. Women at any age who were suffering from chronic pelvic inflammatory disease (PID) attended at the OPD of gynecology Department at Dhaka Medical College Hospital, Dhaka, Bangladesh were selected as study population. Clinically the patients were diagnosed with the presence of at least three of the symptoms like chronic pelvic pain or backache, deep dyspareunia, congestive dysmenorrhea, menstrual irregularities as well as the signs like lower abdominal tenderness, cervical motion tenderness and adnexal tenderness with or without thickening of fornices or mass. Detailed history of each patient was taken and thorough physical examination was performed. Subsequently, each patient were underwent the investigations like CBC, ESR, total count, endocervical swab for culture and sensitivity and ultra-sonogram of lower abdomen. Relevant data from each patient were recorded in a questionnaire. Data were analyzed by SPSS version 21.0 software package. All data were recorded systematically in a preformed data collection sheet. The quantitative data were expressed as frequency and percentage and the quantitative data were expressed as mean with standard deviation.

\section{Result}

A total number of 150 cases were studied. Among 150 cases of chronic pelvic inflammatory disease (PID) majority (54\%) belonged to the age group of 26 to 35 years (Table 1).

Table 1: Age Distribution of the Patients $(n=150)$

\begin{tabular}{|l|c|c|}
\hline Age Group & Frequency & Percent \\
\hline 16 to 25 Years & 50 & 33.3 \\
\hline 26 to 35 Years & 81 & 54.3 \\
\hline More than 35 Years & 19 & 12.4 \\
\hline Total & $\mathbf{1 5 0}$ & $\mathbf{1 0 0 . 0}$ \\
\hline
\end{tabular}

Out of 146 patients $75.3 \%$ were delivered at home, $8.2 \%$ at hospital and $16.4 \%$ cases had their deliveries at home and at hospital also (Table 2).

Table 2: Relationship between Place of Delivery and PID $(n=146)$ 


\begin{tabular}{|l|c|c|}
\hline Place of Delivery & Frequency & Percent \\
\hline Home & 110 & 75.3 \\
\hline Hospital & 12 & 8.2 \\
\hline Home and hospital & 24 & 16.4 \\
\hline Total & $\mathbf{1 4 6}$ & $\mathbf{9 9 . 9}$ \\
\hline
\end{tabular}

Out of 146 patients $63.0 \%$ were delivered by untrained birth attendants at home and $36.99 \%$ were delivered by trained birth attendants (Table 3 ).

Table 3: Relationship between Conduction of Delivery and PID $(n=146)$

\begin{tabular}{|l|c|c|}
\hline Delivery Conducted & Frequency & Percent \\
\hline Untrained birth attendant & 92 & 63.0 \\
\hline Trained birth attendant & 54 & 36.9 \\
\hline Total & $\mathbf{1 4 6}$ & $\mathbf{9 9 . 9}$ \\
\hline
\end{tabular}

Out of 146 patients $54.1 \%$ had history of puerperal sepsis. However, the rest of the 67(45.9\%) cases were normal puerperium (Table 4).

Table 4: Relationship between complication of delivery and PID $(n=146)$

\begin{tabular}{|l|c|c|}
\hline Complication & Frequency & Percent \\
\hline Puerperal sepsis & 79 & 54.1 \\
\hline Normal puerperium & 67 & 45.9 \\
\hline Total & $\mathbf{1 4 6}$ & $\mathbf{9 9 . 9}$ \\
\hline
\end{tabular}

In this study $84.0 \%$ patients had history of MR, 18 percent had spontaneous abortion and 4.7 percent had induced abortion. Out of these 115 patients with history of pregnancy termination, 47.3 percent patients had history of pelvic infection following that event. Also, 2.7 percent gave history of ectopic pregnancy (Table $5)$.

Table 5: Procedure of Termination of Pregnancy among PID Patients $(n=150)$

\begin{tabular}{|l|c|c|}
\hline Pregnancy Termination Event & Frequency & Percent \\
\hline MR & 81 & 54.0 \\
\hline Post-abortion/MR complication & 71 & 47.3 \\
\hline Spontaneous abortion & 27 & 18.0 \\
\hline Induced abortion & 7 & 4.6 \\
\hline Ectopic pregnancy & 4 & 2.7 \\
\hline
\end{tabular}

\section{Discussion}

The exact incidence of PID is unknown because the disease cannot be diagnosed reliably from clinical symptoms and signs, moreover women who have PID present to the general practitioners, gynaecologist and surgeons (Brunham 2015). Hospital discharge registries are poor surrogate markers for the true prevalence of PID. However prevalence of PID is increasing all over the world. Five percent of gynaecological admissions in the hospitals of India and Pakistan are due to PID and in Africa it is 17 to 44 percent (Soper 2010). With this rising incidence of PID and its considerable impact on reproductive health of an individual, attention should be directed towards improved diagnosis and management.

A detailed and methodical study of 150 cases in this series shows highest (54.3\%) incidence of this disease being in the age group of 26 to 35 years. Peterson et al (1991) also showed that women with PID are usually under the age of 25 years. Wiesenfeld et al (2002) showed that 87 percent of the patients belong to the age group 20-35 years. There is similarity between this last study which was conducted in India, with the present study. Laila (1997) also showed that $55.21 \%$ of her patients were in the age group of 26 to 35 years. PID occurs more in younger age group in western countries where the disease is mainly STD - related, but in developing countries, it is mostly non-STD related and occurs in later age group.

Younger age is marked by biological characteristics conductive to the development of PID, such as a lower prevalence of protective chlamydial antibody, larger zone of cervical ecotypy and greater permeability of cervical mucosa (Fortner 2007). A correlation between early coital indulgence and promiscuous sexual 
relationship might explain the very high saplingitis incidence in sexually active teenage girls. However, STD is less important for development of PID in the somewhat older women. In this age group of patients and also in women who have had two or more episodes of PID, anaerobic bacteria is thought to be the aetiological agent. The reason behind this may be the post PID fallopian tubes are more vulnerable to infections by anaerobes. Anatomic changes induced by pregnancy and delivery contribute to an easier access to the vagina for bowel flora (Sciarra 1994). This may lead to an increased occurrence of a type of nonvenereal PID in women of comparatively higher age.

Regarding delivery 75.4 percent were delivered at home, conducted by untrained birth attendants in 63 percent cases. Among them 54.1 percent cases were complicated by puerperal sepsis. Laila (1997) also showed that 56.21 percent of her patients had history of puerperal sepsis. This entails the pathophysiological aspect of PID. Haggerty et al (2006) showed that PID occurred mostly in multipara. But another study by Wiesenfeld et al (2002) revealed that 74.4 percent of PID cases were nulliparous mostly acute cases. These studies therefore, showed that in developing countries the majority of cases were older parous women and in the industrialized countries the majority were younger nulliparous women.

As it has already been proved that STD has an important role in aetiology of PID, the former being related to the sexual activity of a woman and the number of her sexual partners. A survey on the sexual behaviour of USA college girls showed that during the last two decades, there has been a gradual rise in premarital sex amongst them (Buchan et al., 1993). Such a change explains the prevalence of STD and hence PID in young nulliparous women.

Majority of the rural women of Bangladesh depend primarily on untrained or relatively less trained birth attendants and relatives for child birth assistance. They conduct the delivery process in very unhygienic environment, never use any sterile gloves and conduct repeated pelvic examinations even after rupture of the membrane. This gives an opportunity for potential pathogens to pass from the lower genital tract into the normally sterile environment of uterus. It is more common, however, for the infection to remain localized in the pelvis and if effective treatment is not given immediately, there is a danger of chronic pelvic infection with tubal blockage. In a maternal morbidity study, it has been found that 16.7 percent women reported symptoms of PID at postpartum period (Haggerty et al., 2006).

In this study it has been shown that there was history of termination of pregnancy either in the form of MR or abortion both induced and spontaneous in $76.7 \%$ cases. More than fifty percent of them developed sepsis. Laila (1997) showed that 66.08 percent of her patients had history of termination of pregnancy and out of these 55.11 percent had history of pelvic infection following that event. Simms et al (2006) showed that highest incidence of pelvic infection occurred following abortion. It is estimated that 36-53 million induced abortions are performed annually throughout the world of which about 21 million are unsafe abortion ${ }^{51}$. The rates of infectious complications for such procedure depend on precautions and technique. Ideally, MR should be done by trained persons. But in our country it is frequently done by unauthorized or untrained persons. Due to their lack of knowledge of aseptic conditions, PID occurs. The incidence of pelvic infection can also be minimized by screening and prophylactic treatment of women for STD before termination of pregnancy.

Regarding the occurrence of another major morbidity like occurrence of ectopic pregnancy, present study showed that 4(2.7\%) patients gave history of ectopic pregnancy. Wiesenfeld et al (2002) in his study showed that the incidence of ectopic pregnancy in PID was $2.7 \%$ which corresponds to the present study. However, Laila (1997) has found $2.08 \%$ ectopic pregnancy.

\section{Conclusion}

Obstetric events of these patients showed that majority were delivered at home, conducted by untrained birth attendants and more than half of the patients had history of puerperal infection. There is an increasing trend of MR and induced abortion, of which more than fifty percent case were complicated by infection. Though MR is supposed to decrease the incidence of PID, but as the procedure done in our country is by some improperly trained persons without proper aseptic precaution, the incidence of PID is highest among the post MR patients. Safe delivery practice by skilled birth attendant and in hygienic condition should be adopted.

\section{References}


Brunham RC, Gottlieb SL, Paavonen J. Pelvic inflammatory disease. New England Journal of Medicine. 2015;372(21):2039-48

Buchan H, Vessey M, Goldacre M, Fairweather J. Morbidity following pelvic inflammatory disease. BJOG: An International Journal of Obstetrics \& Gynaecology. 1993;100(6):558-62

Fortner KB, editor. The Johns Hopkins manual of gynecology and obstetrics. Lippincott Williams \& Wilkins; 2007.

Haggerty CL, Totten PA, Astete SG, Ness RB. Mycoplasma genitalium among women with nongonococcal, nonchlamydial pelvic inflammatory disease. Infectious diseases in obstetrics and gynecology. 2006;2006

Laila R. Study of 192 cases of chronic PID in GOPD of Dhaka Medical College Hospital (dissertation), Dhaka: Bangladesh College of Physicians and Surgeons, 1997

Peterson HB, Walker CK, Kahn JG, Washington AE, Eschenbach DA, Faro S. Pelvic inflammatory disease: key treatment issues and options. JAMA. 1991;266(18):2605-11

Rivlin ME, Martin RW. Manual of clinical problems in obstetrics and gynecology. 5the Edition. Lippincott Williams \& Wilkins; 2000

Sciarra JJ. Infertility: a global perspective. The role of pelvic infection. ORGYN: Organon's magazine on women \& health. 1994;(3):12-17

Simms I, Stephenson JM, Mallinson H, Peeling RW, Thomas K, Gokhale R, Rogers PA, Hay P, Oakeshott P, Hopwood J, Birley H. Risk factors associated with pelvic inflammatory disease. Sexually transmitted infections. 2006;82(6):452-7

Soper DE. Pelvic inflammatory disease. Obstetrics \& Gynecology. 2010;116(2):419-28

Wiesenfeld HC, Hillier SL, Krohn MA, Amortegui AJ, Heine RP, Landers DV, Sweet RL. Lower genital tract infection and endometritis: insight into subclinical pelvic inflammatory disease. Obstetrics \& Gynecology. 2002;100(3):456-63 